This item was submitted to Loughborough's Research Repository by the author.

Items in Figshare are protected by copyright, with all rights reserved, unless otherwise indicated.

\title{
The materiality of mathematics: presenting mathematics at the blackboard
}

PLEASE CITE THE PUBLISHED VERSION

http://dx.doi.org/10.1111/1468-4446.12037

\section{PUBLISHER}

Wiley @ London School of Economics and Political Science

VERSION

AM (Accepted Manuscript)

LICENCE

CC BY-NC-ND 4.0

REPOSITORY RECORD

Greiffenhagen, Christian. 2019. "The Materiality of Mathematics: Presenting Mathematics at the Blackboard". figshare. https://hdl.handle.net/2134/14295. 


\title{
The Materiality of Mathematics: Presenting Mathematics at the Blackboard
}

Christian Greiffenhagen

\begin{abstract}
Sociology has been accused of neglecting the importance of material things in human life and the material aspects of social practices. Efforts to correct this have recently been made, with a growing concern to demonstrate the materiality of social organisation, not least through attention to objects and the body. As a result, there have been a plethora of studies reporting the social construction and effects of a variety of material objects as well as studies that have explored the material dimensions of a diversity of practices. In different ways these studies have questioned the Cartesian dualism of a strict separation of 'mind' and 'body'. However, it could be argued that the idea of the mind as immaterial has not been entirely banished and lingers when it comes to discussing abstract thinking and reasoning. The aim of this article is to extend the material turn to abstract thought, using mathematics as a paradigmatic example.

This paper explores how writing mathematics (on paper, blackboards, or even in the air) is indispensable for doing and thinking mathematics. The paper is based on video recordings of lectures in formal logic and investigates how mathematics is presented at the blackboard. The paper discusses the iconic character of blackboards in mathematics and describes in detail a number of inscription practices of presenting mathematics at the blackboard (such as the use of lines and boxes, the designation of particular regions for specific mathematical purposes, as well as creating an 'architecture' visualising the overall structure of the proof). The paper argues that doing mathematics really is "thinking with eyes and hands" (Latour, 1986). Thinking in mathematics is inextricably interwoven with writing mathematics.
\end{abstract}

\section{Keywords}

materiality; mathematics; inscriptions; workplace studies 


\section{Introduction}

Sociology has been accused of neglecting the importance of material things in human life and the material aspects of social practices (Goody, 1973; Latour, 2000; Dant, 2006). A prevailing emphasis on the role of consciousness and beliefs in the explanation of social conduct has meant that central concerns of sociology - such as solidarity, authority, and rationality - have been construed in a mentalist rather than materialist manner.

Efforts to correct this have recently been made, with a growing concern to demonstrate the materiality of social organisation, not least through attention to objects and the body. A 'material turn' has been taking place as a result of a variety of influences reaching back, at least, to McLuhan's idea that the form of a medium is constitutive of the organisation of experience in ways much more consequential than those following from the informational content conveyed by it, Foucault's insistence that power is often most decisively effected through control of the body rather than the mind (and his corresponding emphasis on the disposition of spaces and furnishings and on the regulation of posture and movement), not to mention Bourdieu's treatment of cultural practices as installed in the habitus.

For this paper the influence of the subfield of science and technology studies (STS) in reframing traditional conceptions of scientific practices and technological tools is most pertinent (Latour, 2000; Law, 2008). Latour and Woolgar (1979) in their study of a scientific laboratory pointed to the omnipresence and importance of instruments and literary devices ('inscriptions') in scientific practice that had not previously been discussed in studies of science, which had been more preoccupied with the cognitive content of scientific theories rather than the embodied and material practice of scientific work in the laboratory. Latour went on to argue that sociology generally disregarded the role material things have in shaping all aspects of social life, characterizing these 'nonhumans' as "the hidden and despised social masses who make up our morality" (Latour, 1992, p. 227).

In response, there have been a plethora of studies reporting the social construction and effects of a variety of material objects (doors, scallops, bicycles) as well as studies that have explored the material dimensions of a diversity of practices. In different ways these studies have reversed the Cartesian dualism of a strict separation of 'mind' and 'body' and have pointed to the ways that what the mind 'does' is in various ways shaped, determined, even constituted by the body and material artefacts.

However, the idea of the mind as immaterial has not been entirely banished and perhaps lingers most persistently when it comes to discussing thinking and reasoning. The aim of this article is 
therefore to extend the material turn to abstract thought, which is still seen as a purely mental activity done by individuals, using mathematics as a paradigmatic example.

What better example of abstract thought is there than mathematics? Mathematics has been considered as the highest form of pure thought (Plato) and the clearest example of a priori knowledge (Kant) and it still retains the aura of an ethereal and abstract practice. This might explain why, for the most part, sociologists have only rarely studied mathematics or other formal practices. As Latour (1987, p. 246) observes:

[...] almost no one has had the courage to do a careful anthropological study of formalism. The reason for this lack of nerve is quite simple: a priori, before the study has even started, it is towards the mind and its cognitive abilities that one looks for an explanation of forms.

Despite this, there have been attempts to study the material aspects of cognition. For example, Lave (1988) in Cognition in Practice details how shoppers and dieters use a variety of resources (from fingers to cooking utensils) as part of practical arithmetic calculations. Similarly, Hutchins (1995) in Cognition in the Wild emphasizes that calculations done as part of navigating large ships are not done by individuals in their head, but by groups of people using a variety of instruments. However, in these cases people are already involved in practical activities (shopping or navigating) and not concerned with 'abstract thinking' as such. These are not examples of 'pure' or 'abstract' thinking associated with the achievements of mathematicians such as Euclid, Newton, or Hilbert.

On one level, it is of course no big surprise that mathematics is a material practice. Mathematicians doing mathematics rarely only sit and 'think', but typically also scribble on paper or blackboards. When mathematicians present mathematics, they almost certainly will make use of written symbols. Nevertheless, in contrast to the vast number of studies that have detailed different material and embodied aspects of the practices of the experimental sciences, this has rarely been done for the 'conceptual' or 'abstract' sciences (Latour, 2008).

There are only a few precedents for the respecification of mathematics as a purely cerebral activity to one that relies on, in fact is constituted by, material practices. The classic example is Goody's (1977) suggestion in The Domestication of the Savage Mind that the development of (formal) logic is a function of the development of writing. Goody uses this to revisit Lévy-Bruhl's argument that the law of contradiction is less present in 'primitive' societies. Rather than attributing this to a difference in styles of thought, Goody notes that this is tied to the fact that formal contradictions are easier to perceive in writing. With respect to mathematics, Goody remarks that arithmetic operations (such as multiplication) are tied to written developments (such as the multiplication table). It is not that non- 
literate people have no skills in multiplication, but that these are greatly expanded by having written tools available.

More recently, Netz (1999) in The Shaping of Deduction in Greek Mathematics shows how ancient Greek mathematics is grounded in the material practice of Greek mathematicians. Netz argues that the history of mathematics by focusing on what he calls the 'verbal' aspects (written texts and symbols) has neglected other features, in particular, the lettered diagram, which for Netz is decisive for the emergence of Greek mathematics. Netz demonstrates that arguments in geometry rely on writing and pictures, i.e., that text and diagram are interdependent (the text would be difficult to follow without the diagram while the diagram would be too vague without the text).

This paper continues the line of thought initiated by Goody and Netz in recognising that writing (on paper, blackboards, napkins, beermats, or even in the air) and the development of representational techniques are indispensable for doing and thinking mathematics, giving central place to the use of chalk and blackboard through an analysis of video recordings of graduate lectures in mathematical logic.

Although there have been a number of studies that have explored the social and cultural aspects of mathematical practice (e.g., Bloor, 1976; Livingston, 1986; Heintz, 2000; MacKenzie, 2001; Warwick, 2003; Rosental, 2008), none of these provided video recordings of mathematicians 'doing' mathematics. This paper is part of a bigger project that aims to bring the 'workplace studies' approach (e.g., Heath et al., 2000; Llewellyn, 2011) to the workplace of mathematics by studying the mundane practices of mathematicians. The data for this paper is drawn from a first study, which investigated the presentation of mathematics in graduate lectures, while a second study, based on a year-long video-based ethnography of the weekly supervision meetings between a professor and his doctoral students, was able to observe the processes involved in creating new mathematics (Greiffenhagen and Sharrock, 2012).

Lectures are a perspicuous way to exhibit the written nature of mathematics, since they involve a great deal of writing. It is not untypical for a lecturer to fill several blackboards during one lecture. Furthermore, lecturers typically write the definitions, theorems, and proofs out in full (i.e., do not just write a few keywords or a sketch on the board). Lecturers spend a lot time 'writing-talking' at the blackboard, i.e., writing things on the board while simultaneously saying them aloud. The aim of this paper is to fill a gap that was identified by Livingston (1986, pp. 225-226) many years ago when he observed that "the exact manner in which blackboard displays are produced has not [...] been subjected to examination" (for a notable exception see Barany and MacKenzie, forthcoming). 


\section{Blackboards and mathematics}

Blackboards are of almost iconic status in mathematics. ${ }^{1}$ The typical image of a mathematician is a person standing in front of a blackboard using chalk to write strange symbols. This is certainly how many famous mathematicians or theoretical scientists such as Einstein have been photographed (Barthes, 1972 [1957], p. 69). Similarly, many mathematicians today choose to use a photograph of themselves in front of a blackboard on their homepage. Blackboards also feature heavily in depicting mathematics in movies. ${ }^{2}$ One famous example includes a blackboard in the corridor outside a classroom in Good Will Hunting, which enables the janitor (played by Matt Damon) to display his genius by secretly writing solutions to supposedly difficult problems.

A short visit to a mathematics department or research institute also demonstrates the omnipresence of blackboards, for example:

- teaching rooms with not just one, but two or more blackboards mounted next to each other (see Figure 1.A);

- lecture theatres with several 'movable' blackboards on top of each other (Figure 1.B);

- seminar rooms with two or three walls covered in blackboards (Figure 1.C);

- corridors with long blackboards (Figure 1.D);

- offices with one or more blackboards, even on the inside and the outside of office doors (Figure 1.E);

- blackboards in a variety of other spaces, including terraces (Figure 1.F), elevators (Figure 1.G), and even bathrooms (Figure 1.H).

\footnotetext{
${ }^{1}$ I use the term 'blackboard' synonymously with 'chalkboard', but distinguish these from 'whiteboards'.

2 Oliver Knill has collected many instances of "Mathematics in the Movies": http://www.math.harvard.edu/ knill/mathmovies/
} 


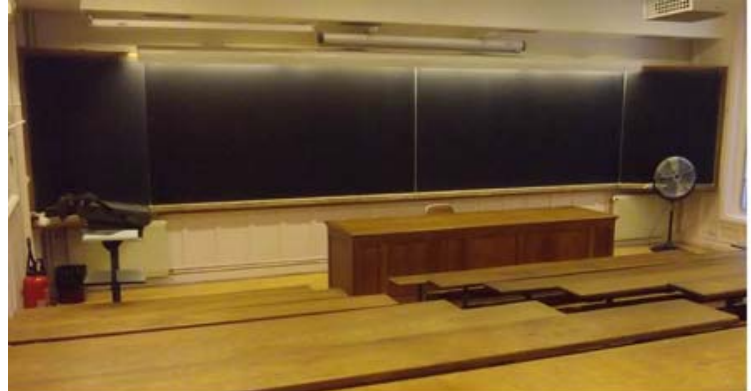

A

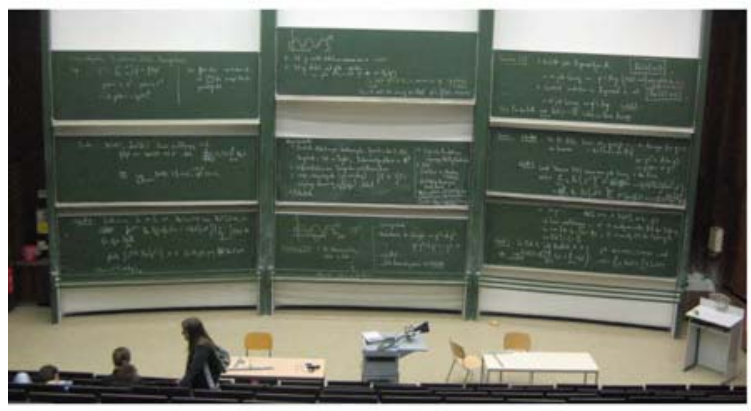

B

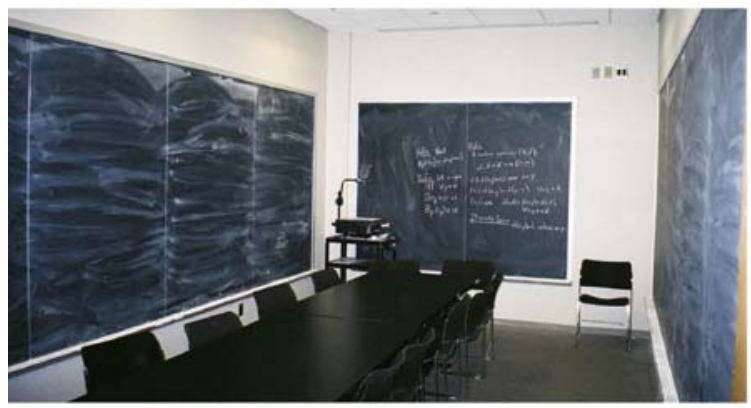

C

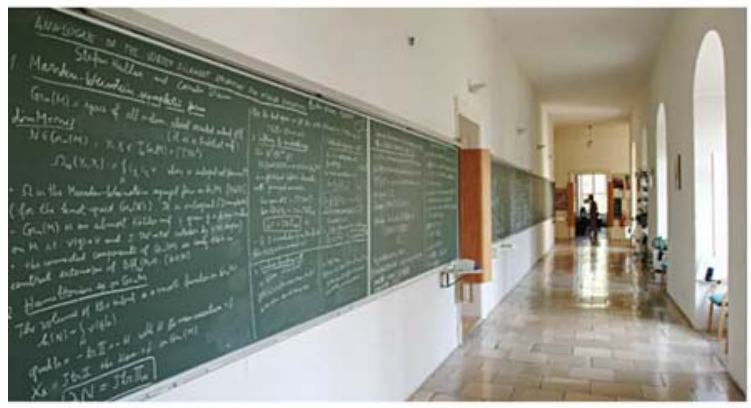

D

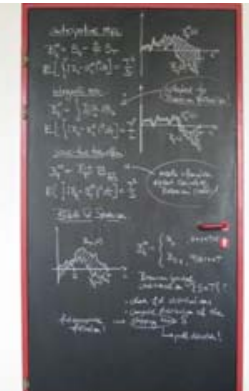

$E$

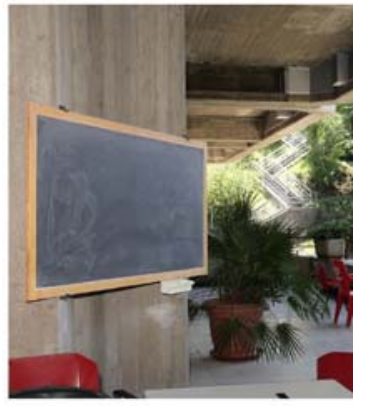

$\mathrm{F}$

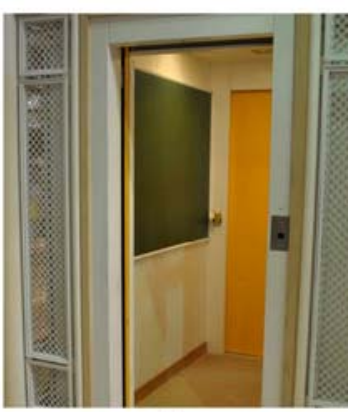

G

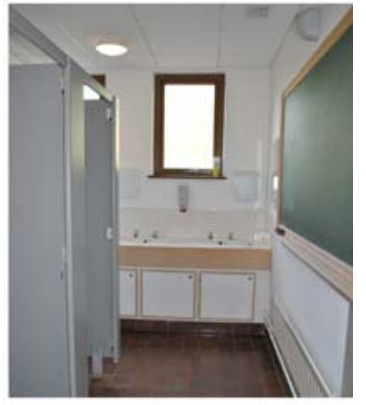

$\mathrm{H}$

Figure 1: a variety of blackboards ${ }^{3}$

${ }^{3}$ I would like to thank the many people who have helped me to track down photographs of various blackboards (unfortunately it was not possible to include all of them). The photographs are reproduced with the kind permission of the copyright holders: Institute Henri Poincaré (A), Peter Kern (B,E), Robert Landsman (C), Erwin Schrödinger International Institute for Mathematical Physics (D), Abdus Salam International Centre for Theoretical Physics (F), Isaac Newton Institute for Mathematical Sciences (G, H). 
Blackboards are a familiar part of modern educational settings since the nineteenth century (Kidwell et al., 2008; Wylie, 2012). According to Hamilton (1990, p. 75) they became commonplace as the result of two developments: a change from lecturing to question-answer teaching and the emergence of 'cohort teaching', i.e., teaching groups of pupils as one unit.

There have only a few studies that have explored the role of the boards as part of educational or scientific practice (e.g., Suchman and Trigg, 1993; Ochs et al., 1994; Greiffenhagen, 2000; Pitsch, 2007; Kalthoff and Roehl, 2011). Of particular importance is Warwick's (2003) pedagogical history of the Mathematical Tripos at Cambridge University, in which he gives a brief account of how blackboards were gradually incorporated into teaching advanced mathematics. According to Warwick, until the early $19^{\text {th }}$ century lectures were predominantly oral. Blackboards were slowly introduced as many students moved away from lectures and instead sought out coaches. While such coaches initially worked with only one or two pupils sitting together in front of a piece of paper, blackboards allowed them to talk to several pupils simultaneously (p. 234).

Lecturing at the blackboards is still the most common form of instruction for both undergraduate and graduates students in mathematics. In contrast to other subjects, lectures rarely use modern presentation tools such as overhead projectors or beamers (although these have become more common in research presentations).

\section{A proof at the blackboard}

In order to illustrate some aspects of the work of demonstrating mathematics at the blackboard, this paper focuses on one lecture from a graduate course in mathematical logic, in which the lecturer gives a proof of the completeness theorem for propositional logic.

Propositional logic (also referred to as propositional calculus or sentential logic) is the relatively elementary part of formal, symbolic logic that deals with how propositions (also called sentences), statements that assert something, are combined by logical connectives such as 'and', 'or', 'not', or 'implies'. Formal logic distinguishes between semantic truth (in which sense sentences can be said to hold in some world) and syntactic provability (in which sense sentences can be said to follow from another). The completeness theorem establishes a correspondence between the two notions of semantic truth and syntactic provability for propositional logic. In 1930 Gödel published a completeness theorem for the more powerful first-order logic (which in addition to logical connectives also contains quantifiers such as 'for all' and 'there exists'), a year before he published his paper containing the famous incompleteness theorems (which refer to a different sense of 'completeness'). 
The completeness theorem had already been formulated in the previous lecture, but the main proof still remains to be done (and takes almost forty minutes to complete).

There were two blackboards in this seminar room. What is noteworthy is that the lecturer, who arrived before the official starting time of the lecture, writes something on the blackboard before most of the students arrived: He writes a 'lemma' (a subsidiary or auxiliary result) on the right side of the right board (Figure 2).

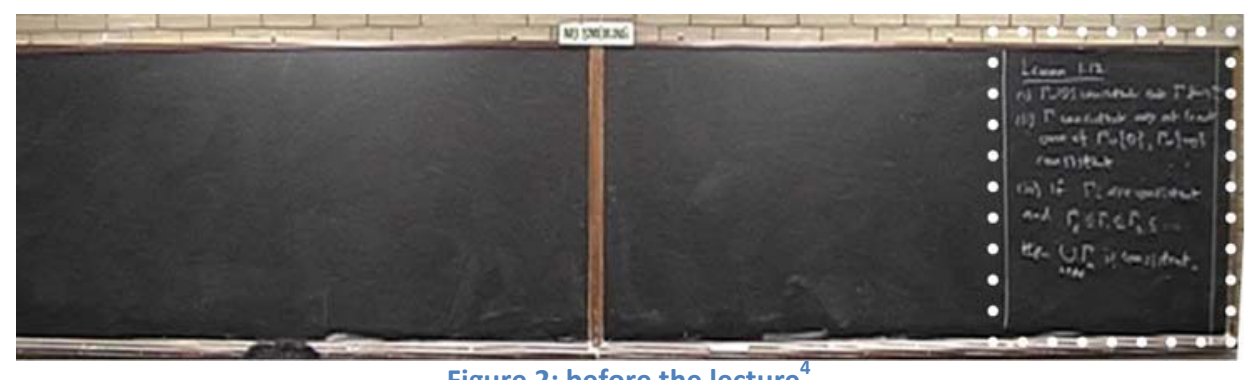

Figure 2: before the lecture

This is interesting for several reasons.

Firstly, it highlights the interconnectedness of mathematics: mathematical arguments rely heavily on results proven previously, either in the same course or in other courses. This is why Wittgenstein (1978, VII, §67) characterized mathematics as a "network of norms" (my emphasis). Here, this interconnectedness has a material manifestation: the lecturer writes out a result that has been established in a previous lecture.

Secondly, by writing out this result from the previous lecture the lecturer indicates to students that it will be referred to in the arguments developed in this lecture. The lemma consists of three cases and students can expect that all these cases will be 'used'. This prospective character is already indicated by labelling this result a 'lemma' (rather than a 'theorem'): it is an auxiliary result, but since the lemma had only been established, not 'used', in the previous lecture, it still remains to be seen to what it is auxiliary.

Thirdly, the lemma is not written 'anywhere', but at the side of one of the two boards. This has the advantage that it is easily 'findable' (if the lecturer wants to refer to it) and also 'out of the way' (leaving a lot of blank space for the enfolding writing). Indeed, the top left corner and the top right

4

Lemma 1.13

(i) $\Gamma \cup\{\theta\}$ consistent $\Leftrightarrow \Gamma \nvdash \sim \theta$

(ii) $\Gamma$ consistent $\Rightarrow$ at least one of $\Gamma \cup\{\theta\}, \Gamma \cup\{\sim \theta\}$ consistent

(iii) If $\Gamma_{\mathrm{i}}$ are consistent and $\Gamma_{0} \subseteq \Gamma_{1} \subseteq \Gamma_{2} \subseteq \ldots$, then $\bigcup_{n \in \mathbb{N}} \Gamma_{n}$ is consistent. 
corner were the typical places where lecturers would write down definitions or theorems that had been previously established at.

Having written out the lemma, the lecturer waits until the starting time before beginning the lecture: he initially faces the class (line 1), but quickly turns towards the board and starts writing while talking (line 3):

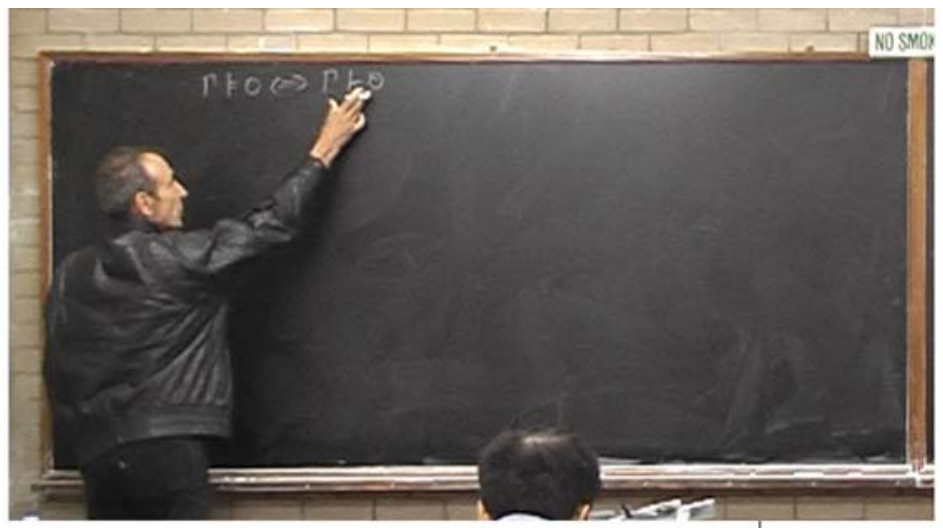

I Okay. So I'm sure you'll remember where we're up to, cos you've probably been pretty

2 excited about it all. We're proving the completeness theorem for the sentential calculus.

3 So this is- ((starts writing)) >tells you that Gamma logically implies theta if and only if

4 there's a proof of theta ((finishes writing)) from Gamma.This side ((points at LHS))

5 talking about infinite number of things, possibly. This side ((points at RHS) $)$ just talking

6 about finite little proof.

Figure 3: beginning of lecture

The lecturer begins the lecture by reminding students that he is in the process of proving a particular theorem, the completeness theorem for the sentential (propositional) calculus, which in symbols can be expressed as: $\Gamma \vDash \theta \Leftrightarrow \Gamma \vdash \theta$. This states that if $\theta$ follows from $\Gamma$ 'semantically' (i.e., every valuation that makes $\Gamma$ true also makes $\theta$ true), then $\theta$ also follows from $\Gamma$ 'syntactically' (i.e., there is a formal proof of $\theta$ from $\Gamma)$, and vice versa.

The lecturer proceeds by telling the students that one direction (from the right hand side [RHS] to the left hand side [LHS]) is "straightforward" and has already been established in the previous lecture. What remains to be shown is the other direction (from LHS to RHS), which the lecturer intends to establish through a proof by contradiction.

The lecturer erases the theorem and in its place writes the first line of the proof, namely the assumption of the proof-by-contradiction: 

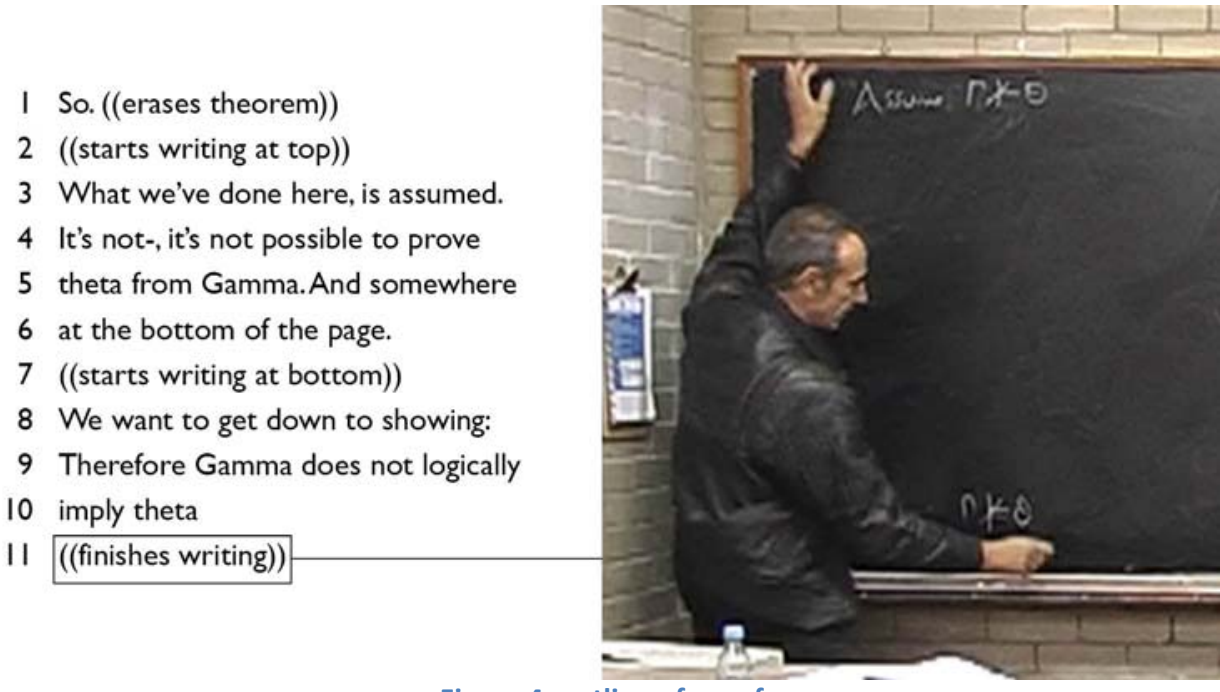

Figure 4: outline of proof

Having written the first line of the proof, "Assume $\Gamma \Vdash \theta$ ", the lecturer does not continue with the proof by writing down the next step, but instead writes down the 'end' of the proof, which he writes at the bottom of the board: " $\Gamma \notin \theta$ ". This is noteworthy for two reasons:

Firstly, the lecturer finds a way of visually expressing that proving is a directed activity. When mathematicians write out a proof (or try to find a proof), they have a general goal ("where we want to get down to") in mind. Here, the lecturer writes this goal at the bottom of the board, visualising that the proof is supposed to lead from the 'top' (the assumption) to the 'bottom' (the conclusion). In a way, the lecturer is painting a visual outline of the proof. This is something has been noted by Weber (2004, p. 121) who describes a lecturer who "would list his assumption at the top of the blackboard and stating his desired conclusion at the bottom".

Secondly, the lecturer speaks of "the bottom of the page", i.e., refers to the writing on the blackboard as resembling the writing on a 'page'. This illustrates the way that proofs in mathematics are written arguments and are treated as thus. It also fits with Warwick's observation above that before the use of blackboards, coaches would write on paper with one or two pupils sitting next to them. Blackboards allow preserving features of this situation in a way that makes the writing visible to a large cohort of students.

Lecturers in other ways exhibited the written nature of the subject matter and the fact that writing on the blackboard resembles the writing in a textbook or journal article. In another lecture, the lecturer wrote (rather than just said) on the board "as for T above" and then pointed to this T, which was located towards the right (and therefore not physically "above") on the blackboard. This closely resembles the conventional writing style (also employed in this article) of speaking of "above" in the sense of "before" or "previously in this argument". In other words, "above" referred to the temporal enfolding of the written argument rather than the actual physical location of the board. 
The lecturer then continues with the proof by writing down an implication that follows from the assumption, namely that the set $\Gamma \cup\{\sim \theta\}$ is consistent, which he writes next to the assumption, connected through the symbol ' $\because$ ' ("therefore"). He draws a line under the assumption, indicating that these two steps constitute one 'block' or 'chunk' in the developing argument. He also draws a vertical line, effectively separating the left board into two columns (Figure 5, left board).

Before continuing the proof, the lecturer then draws attention to the lemma on the right side of the board (that had been written prior to the lecture):

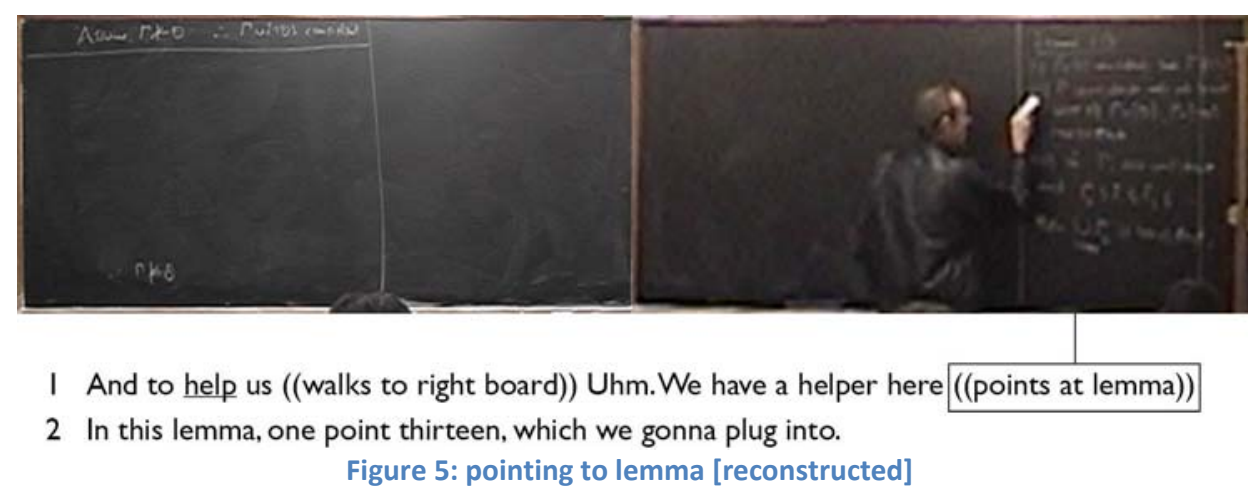

The lecturer walks from the left to the right board, points to the lemma, and explains that it is "a helper", which he can use ("plug into") when developing the proof that will lead from the assumption to the desired conclusion.

The lecturer has provided students with a visual outline of the general 'architecture' of the proof:

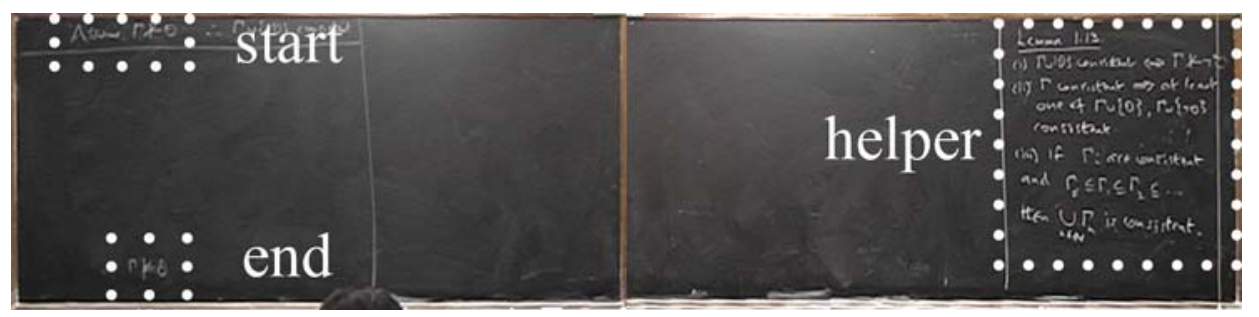

Figure 6: 'architecture' [reconstructed]

The top left corner contains the assumption (starting point), the bottom left corner their goal (end point), while the right side of the board contains the main tool ('helper') for getting from the assumption to the goal. In doing so the remaining blank space, in particular, between the start and the end, has been transformed: it is no longer simply an empty, blank space, but now a 'pregnant' space that is waiting to be filled - with the steps that will lead from the assumption to the goal.

After all this 'stage setting', the lecturer can proceed with the proof. Figure 7 depicts the next three 'steps' the lecturer writes down on the board. 


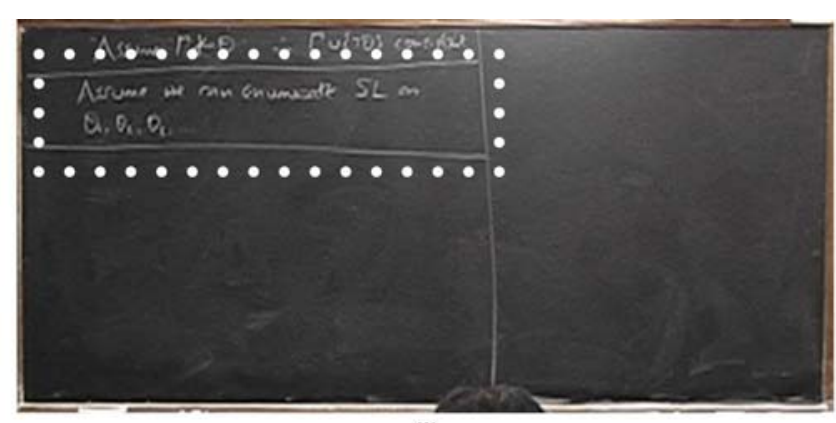

(i)

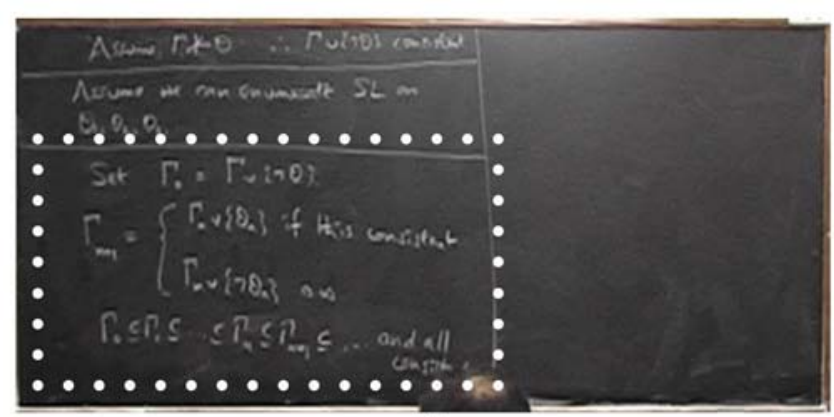

(ii)

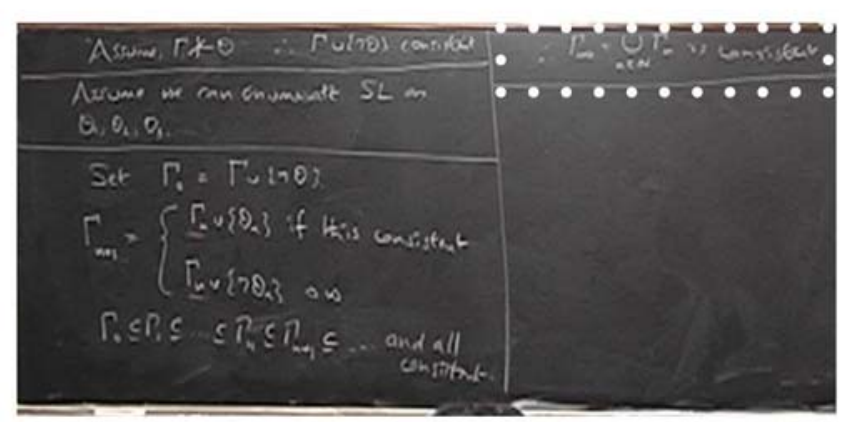

(iii)

Figure 7: next three steps

In these three steps, the lecturer:

(i) introduces an assumption and mentions that the appendix of the lecture notes contains a proof that proceeds without the assumption;

(ii) defines a sequence of sets and demonstrates two properties of this sequence: firstly, that it is an increasing sequence and, secondly, that each set in the sequence is consistent;

(iii) and defines a new set, $\Gamma_{\infty}$, and proves that this set is consistent.

Each of these steps is marked as a step through the use of lines, resulting in a number of 'boxes'. These boxes visually highlight which sentences and symbols 'go together'. The left board now consists of four boxes, where each of these boxes contains a major step in the development of the proof. Lines and boxes are an omnipresent device in communicating mathematics (Livingston [1986, p.49] and Nemirovsky and Smith [2011]). They are part of what Coleman (1988, 1990) calls 'paragraphy' and make visible that the proof is not a series of linear, homogeneous steps, but rather consists of 'chunks' (major steps), which can take different shapes (e.g., just one or several lines). 
While proving the two properties of the sequence of sets, the lecturer at various points refers to the lemma on the right side of the board, either by quickly pointing towards it or, in two instances, even walking to it. He also refers to it when proving that the set $\Gamma_{\infty}$ is consistent, before summarising the way that the different parts of the lemma have been used:

I And therefore ((starts writing)) Gamma infinity, which will be defined as the union of all

2 these Gamma ns, is consistent. ((finishes writing)) And that's by: ((walks to right board))

3 ((points at lemma)) this part here, part three. So we've used all these bits straightaway,

4 isn't that nice? We've brought this toolbox and now we've used all of the tools right in the

5 first-, huh, in the first half page of the proof. That's good.

Figure 8: use of the lemma

The lecturer calls attention to the fact that the lemma has been used and that all of it has been used. This highlights that what is presented here is an organised body of knowledge. When the students encountered the lemma in the previous lecture, it was possibly not clear why these results had to be proved. However, there was an expectation that in proof of the next theorem (to which the lemma is auxiliary), these cases would be used. In other words, not only is the body of mathematical knowledge organised, it is also organised in an lean fashion (proving just what needs to proved, no more or less). The lecturer's remarks about having "used all the tools" "in the first half page of the proof" exhibits an orientation to the neatness with which things have been fitted together. Note that the lecturer again likens the blackboard to a piece of paper when he speaks of "the first half page of the proof".

The lecturer then writes down two properties of the just-defined set $\Gamma_{\infty}$ that he aims to establish:

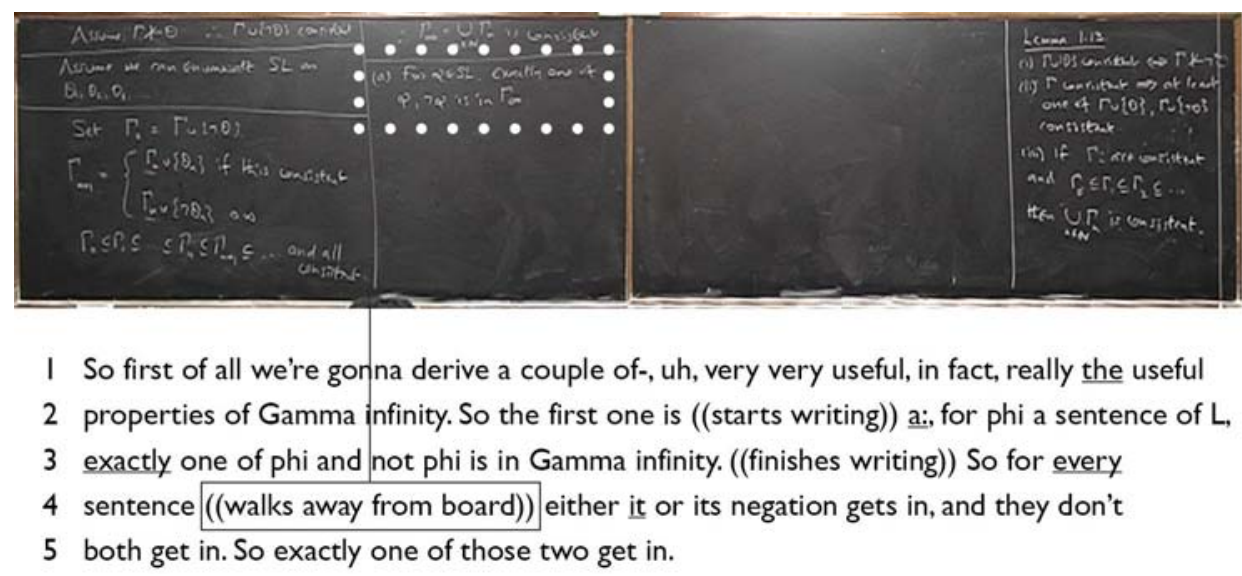

Figure 9: property (a) [reconstructed]

Having written down the first property ("fact") of the set $\Gamma_{\infty}$, the lecturer quickly moves on to prove it, using both the right board and the space below what he has just written on the left board. 


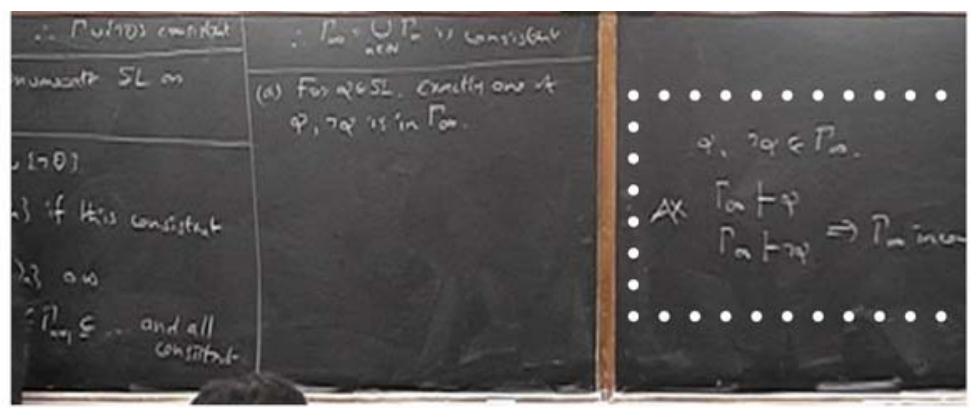

(i)

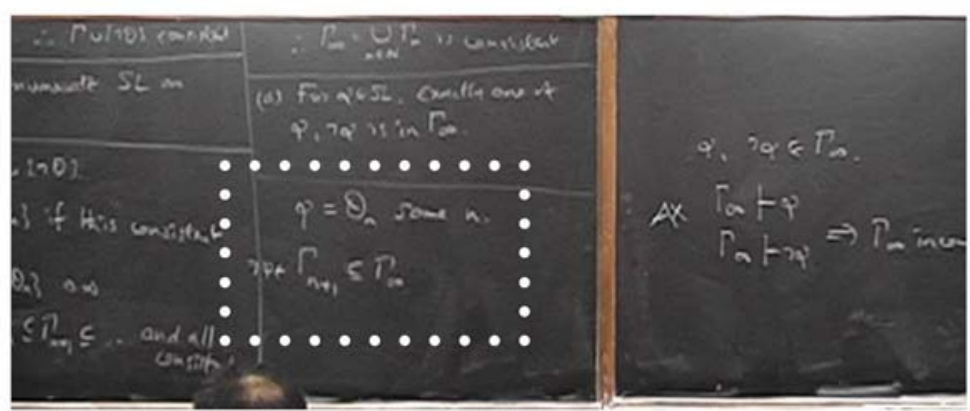

(ii)

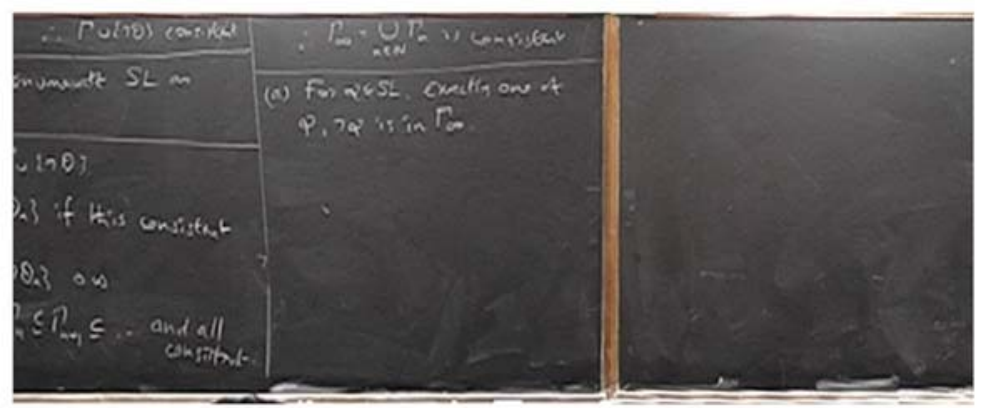

(iii)

Figure 10: proof of property (a) [reconstructed]

The lecturer:

(i) demonstrates that not both $\varphi$ and $\sim \varphi$ can be in $\Gamma_{\infty}$ (written on left side of the right board);

(ii) shows that at least one of $\varphi$ and $\sim \varphi$ has to be in $\Gamma_{\infty}$ (written below to-be-proven property on the left board);

(iii) finally, erases both parts of the proof.

The lecturer typically first writes down a proposition that he wants to establish and then goes on to prove it (either through a quick verbal argument or through a written argument on the board). In other words, the lecturer follows Gillman's $(1987$, p. 6) advice "state first, prove second". This holds both for the main theorem, which was stated at the beginning of the lecture and is currently being proven, as well as individual steps within the overall proof. For example, having written the definition of $\Gamma_{\infty}$, the lecturer first claims that the set is consistent and then provides an argument why this is the case (Figure 8). Here, the lecturer first writes the property of $\Gamma_{\infty}$ before writing-talking a proof. 
Furthermore, in contrast to the writing so far, which was tight and 'economical', the proof of property (a) is written in a rather 'loose' (space consuming) manner: it is written in the middle of the right board (thereby leaving a lot of blank space above it) and is also written with larger lettering and wider spacing (thereby taking up more space than the writing on the left board). It is also written outside the unfolding linear sequence of the proof (which would continue below the property, i.e., on the left board). Instead, it is written literally 'on the side', on the right board, marking it as a 'side proof'.

Having written-talked the proof of property (a), the lecturer erases both parts of the proof without any verbal comments (Figure 10.iii). Lecturers typically try to avoid erasing what they have just written in order to give students time to take notes or to just look at the argument (Krantz, 1999, p. 41). Lecturers said things like "Right. Let's go over ((looks around)) here, perhaps, because I don't want to rub it off immediately", or even provided an apology for going against this rule ("Sorry to wipe that straight off, that's bad form."). However, in this instance, the lecturer erases the two parts of the 'side proof' without any comment, indicating that he thinks that it should be clear to students that the proof was an 'aside' that could quickly be erased.

The lecturer continues to use the board in this way when writing down the second property (which is written on the left board) and its proof (which is written on the right board):

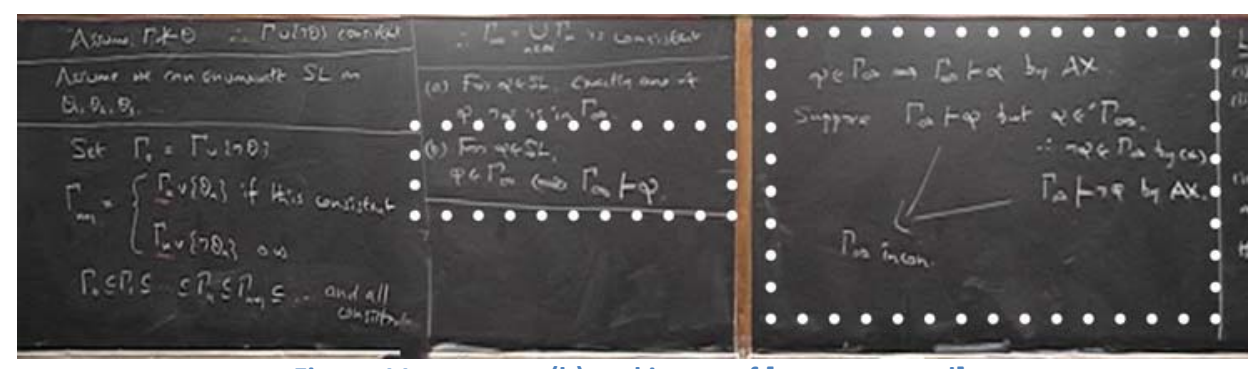

Figure 11: property (b) and its proof [reconstructed]

The proof of property (b) is again written in a 'wasteful' manner, taking up almost the whole of the right board (although it only constitutes one 'step'). Compare this with the tight organisation of the main steps on the left board. As with the proof of the first property, this proof is immediately deleted, without any additional comment.

In effect, the lecturer has separated the blackboard into three 'regions':

- the first region (right side of right board) is reserved for the result from the previous lecture;

- the second region (left board) is used for the main steps of the unfolding proof;

- the third region (left side of right board) is used for 'scratch work' and 'side proof' (for proofs of the steps written down in the second region). 
The lecturer proceeds with the main argument by defining a valuation $V$ (a function that assigns truth values 'true' or 'false to the variables of the formal language) by $V(p)=1 \Leftrightarrow p \in \Gamma_{\infty}$ for $p \in L$.

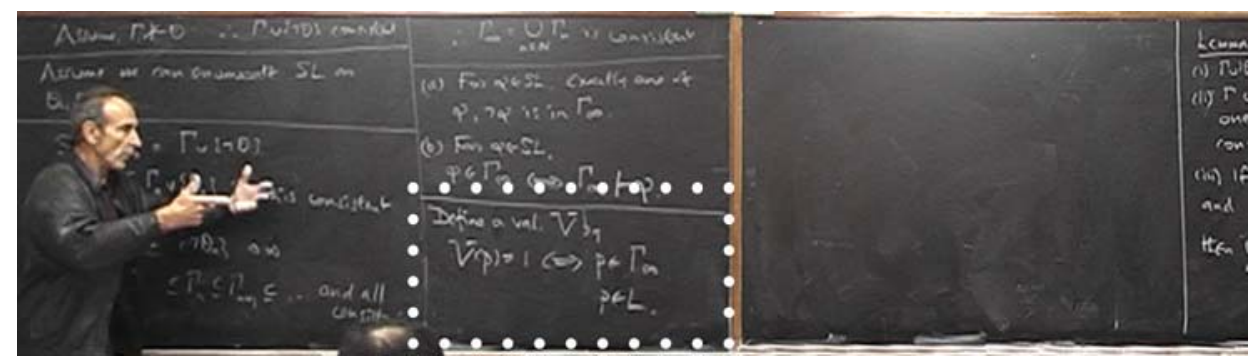

Figure 12: next step (defining a valuation) [reconstructed]

At this stage of the proof, the left board has been completely filled. Where should the next step of the proof be written? The lecturer could continue to write on the right board - but that area is being used for 'scratch work'. Consequently, the lecturer needs to find space on the left board. Which bit should he erase?

He could, of course, erase the top left box, i.e., erase what he has written first (in effect following a 'first in, first out' procedure). Indeed, this is what sometimes happened in these lectures. However, in this instance, the lecture does not do this (presumably, because he wants to keep the starting point of the argument visible throughout this long proof). Instead, he chooses to erase the second box:

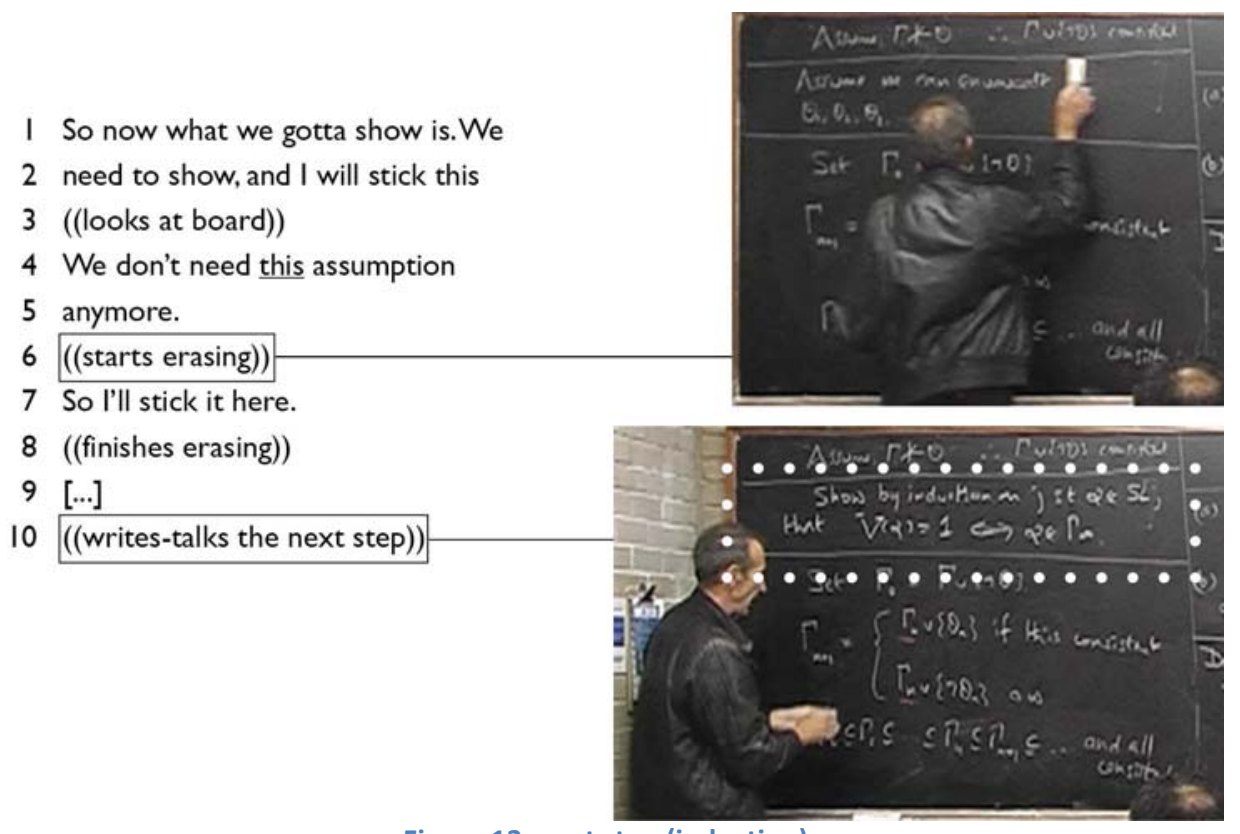

Figure 13: next step (induction)

The lecturer takes some time examining the board, before deciding that he does not "need" the assumption in the second box anymore, which he therefore erases. In the now available space he writes down the next step in the main argument, namely that he intends to show, through an inductive argument, that $V(\varphi)=1 \Leftrightarrow \varphi \in \Gamma_{\infty}$. 
Having erased one box and immediately filled it, the lecturer is again faced with a 'full' blackboard and needs to find another box to delete. He decides to erase the box below the current one, indicating again that he does "need" it anymore. He immediately fills the box with the beginning of the inductive proof, which consists of a 'base step' (which the lecturer indicates follows from the definition of $V$ ) and a number of 'inductive steps'. In this case, there are four such steps and the lecturer writes these down.

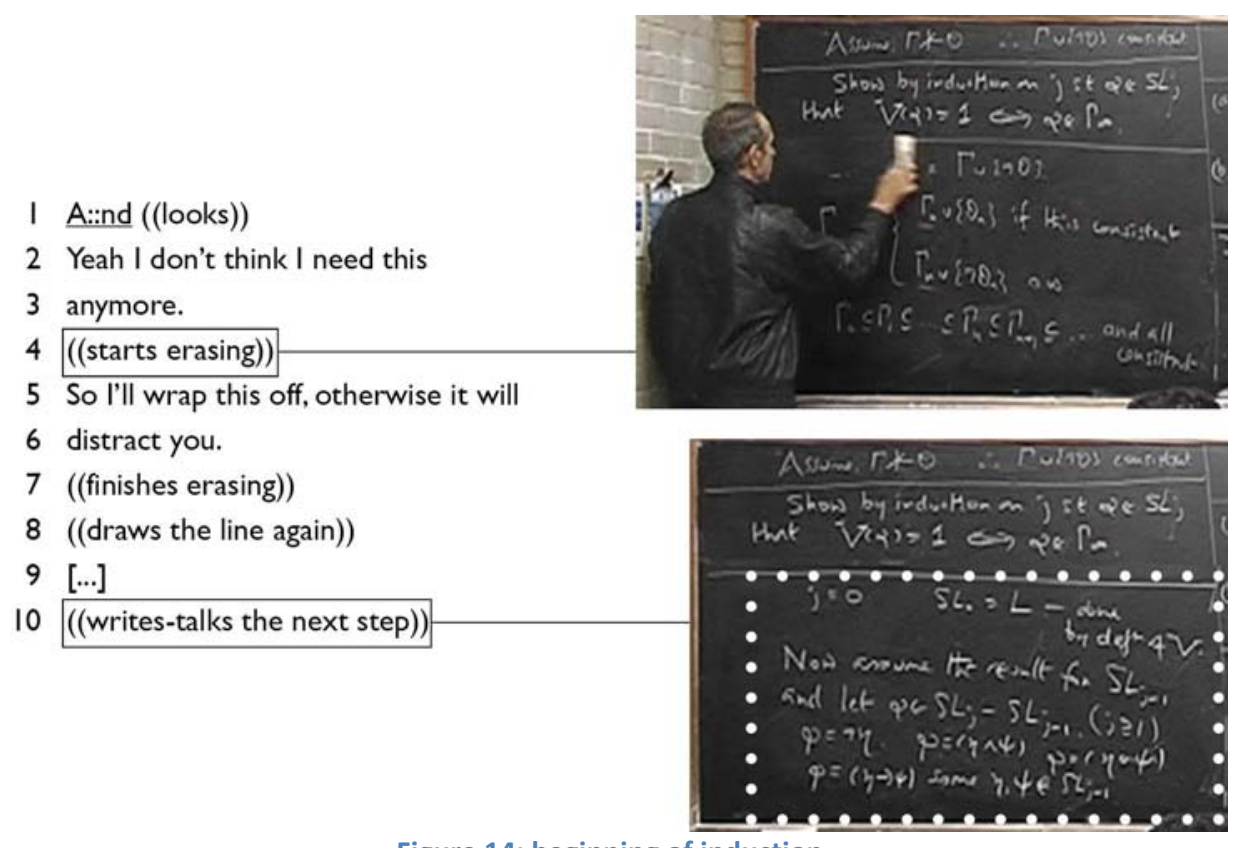

Figure 14: beginning of induction

While the 'side proofs' of the two properties of $\Gamma_{\infty}$ (Figure 10 and Figure 11) were deleted without any comment, in these two instances (Figure 13 and Figure 14), the lecturer provides an account why these boxes can be erased: "we don't need this assumption anymore" and "I don't think I need this anymore". The lecturer thus indicates that in what follows he does need to make reference to these items. While asides or 'side proofs' can easily be erased, the lecturer seems to be reluctant to erase parts of the main argument. If parts have to be erased, they should ideally have 'played their part'. Of course this is not always possible. What is interesting is that erasing parts of the boards constitutes prospective analysis of the yet-to-be-completed proof.

The lecturer then produces proofs for all four cases of the induction. Since these are in a certain sense 'side proofs', they are written again on the right board, just as the proofs of the two properties of $\Gamma_{\infty}$ before. The next figure captures the proof of the first case: 


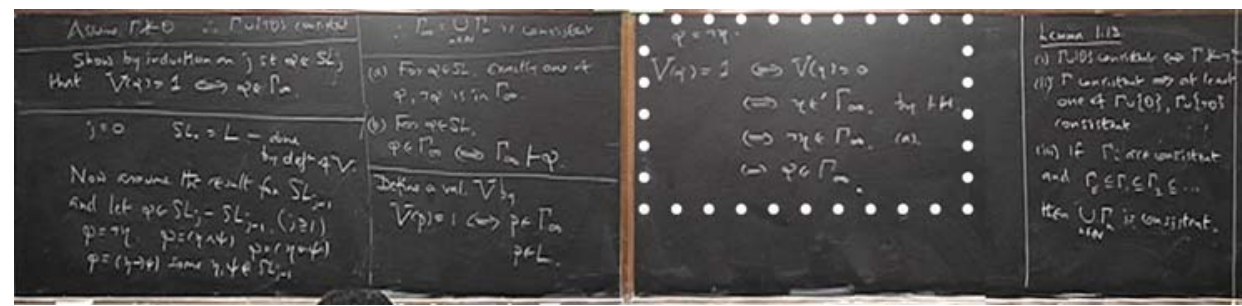

Figure 15: first case of induction [reconstructed]

Going through all four cases takes just over twenty minutes and is written entirely on the right board. Since this means that only limited space is available, the lecturer needs to frequently erase what he has written.

We join the action after the lecturer has finished the fourth and final case and returns to the left board. He points to the proposition that he set out to prove through these inductive cases, $V(\varphi)=1 \Leftrightarrow \varphi \in \Gamma_{\infty}$, erases the box below it, and immediately continues to write:

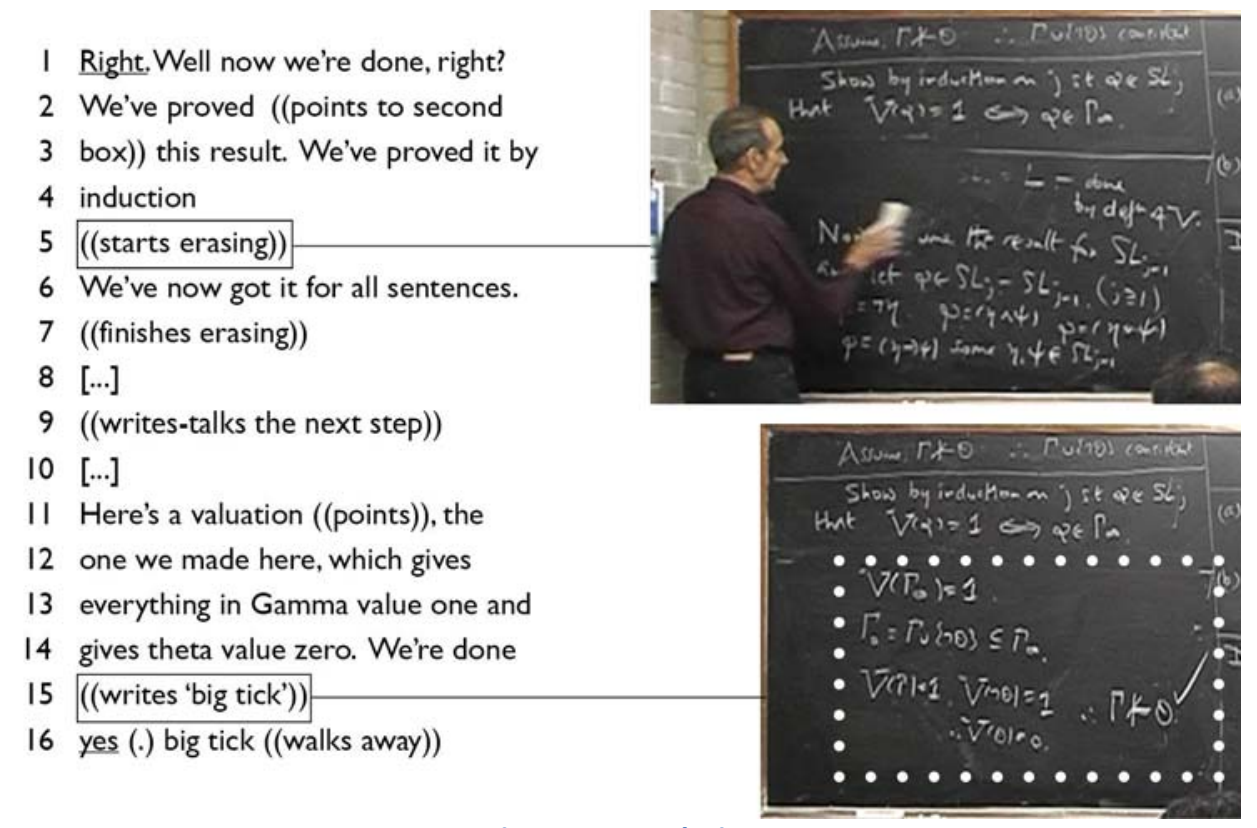

Figure 16: conclusion

Having erased the space below the just-established proposition, the lecturer quickly writes down the final steps of the proof, finishing with an audible outbreath and "we're done" (line 8), which gets visualized through a "big tick" on the board.

\section{Blackboards revisited}

Blackboards seem to have particular properties, 'affordances', that make them especially suitable for the presentation of mathematics. Conversations with about a dozen mathematicians (often contacted via email) confirm this. All of them expressed a strong preference of using boards rather than computer projections for giving lectures and research talks. They also voiced a general preference of blackboards over whiteboards. 
It seems that in many universities blackboards are being replaced by whiteboards or other presentation devices. Academics from most disciplines seem to except this, but there is widespread resistance from mathematicians, who are fighting to keep 'their' blackboards. Several of my respondents told of 'battles' with the administration to have blackboards installed in, or not to be removed from, teaching rooms. One reported that they have "for many years been battling with Estates and Services to retain blackboards in the teaching rooms that we use". Another wrote: "The department [...] moved to a new building about three years ago. We fought a long hard battle to have blackboards in the seminar rooms but eventually got them." Yet another mentioned that blackboards "are still around, but we have to fight otherwise they disappear. The new teaching building, for example, doesn't have any blackboards any more". Respondents also reported that administrations see blackboards as "old-fashioned" and "not sexy enough" for modern universities and have argued that using blackboards may be damaging for electrical equipment in lecture theatres (as a result of chalk dust and the water used for cleaning).

In research institutes, in contract, there has been an attempt to increase the presence of blackboards. For example, the Isaac Newton Institute for Mathematical Sciences in Cambridge has blackboards in every room. Similarly, the Perimeter Institute for Theoretical Physics in Canada has blackboards not only in the seminar rooms, but also in various public areas. ${ }^{5}$ The director of the Institute Henri Poincaré (IHP) in France wrote to me:

IHP takes pride in having many blackboards, large blackboards. The main blackboard in our main lecture hall is a superposition of three blackboards, the upper two are remote commanded, so this is a really high blackboard. Only one company in France continues to repair this kind of blackboards, but we cherish it too much to even think of getting rid of it. Generally speaking, we shall increase the size and number of blackboards. In the cafeteria, I hope to transform a whole wall into 'blackwall'. In my office, the size of the blackboard was increased, this was the first thing I asked when I arrived.

When I asked respondents why they preferred blackboards over other presentational devices, they gave a number of 'functional' explications. ${ }^{6}$ In particular:

- Speed. Having to write out a proof on the blackboard slows the lecturer down and makes it therefore easier for the listener to follow the argument.

\footnotetext{
${ }^{5}$ See the photographs at the Flickr gallery: http://www.flickr.com/photos/perimeterinstitute/

${ }^{6}$ See also the comments on the web forum MathOverflow on: "What's so great about blackboards?" http://mathoverflow.net/questions/5936/whats-so-great-about-blackboards-closed
} 
- Space. Blackboards, due to their size, allow the presenter to have a lot of writing visible without needing to erase too often. This explains why many lecture theatres have a large number of blackboards available (see Figure 1).

They also mentioned two specific advantages of blackboards over whiteboards:

- Visibility. The writing on blackboards (white on black) as being more easily visible from a distance than the writing on whiteboards (black on white).

- Legibility. A number of mathematicians commented that presenters tend to write more clearly with chalk on a blackboard, but write smaller and less clearly with a pen on a whiteboard. Presenters tend to use their whole body when writing with chalk on a blackboard, but only their hand when writing with a pen on a whiteboard.

The most interesting fact mentioned for the preference for blackboards has to do with the nature of the mathematical knowledge communicated. Many mathematicians commented that it is important that a presenter has to write out the proof on the board (rather than simply display it on a slide and then point to it), since this makes visible the process of mathematical reasoning.

One respondent wrote "Blackboards are best for maths (in my opinion) because [...] the need to see ideas materializing in front of you". Another stated that by using blackboards "mathematics becomes visible as a process, not just as a product. This is particularly important in teaching." Yet another reflected: "In math, we are not just teaching facts, but a way of doing things. Presenting this as a sequence of (well-prepared) computer slides will not give them the right impression of how mathematics develops, and thus miss one of the crucial points of why we still have lectures." This resonates with the observation by Halmos (1970, p. 149) that "the blackboard [...] provides the opportunity to make something grow and come alive in a way that is not possible with the printed page". What this paper has shown are some of the ways in which a lecturer can use the blackboard to make visible the processes and the structures of mathematical reasoning.

Perhaps the simplest form of this is the use of lines and boxes to group items on the board together, creating identifiable 'chunks', which make visible the organisation of the blackboard content. It would be easy to dismiss such features as trivial, but that would be a mistake. The same blackboard content without any such lines would be much more difficult to apprehend (Coleman, 1988, p. 247). Proofs can be thought of as a number of 'steps' on a ladder and the lecturer uses lines and boxes to indicate which parts constitute a step.

The lecturer can also designate particular regions of the board for specific purposes. For this proof, the right side of the right board was the space reserved for an important previous result, the left 
board the area for the main steps in the proof, while the remaining space of the right board was used for asides and 'side proofs' (Krantz, 1999, p. 40). Lecturers typically mark these both through their placement (either literally on the side of the board, or in the middle of an empty board, taking up more space than necessary) and the way they are written (very large or very small letters and spacing).

Lecturers also use the blackboard to create a visual outline of the 'architecture' of the proof (Figure 6). By writing his assumption at the top and the goal of the proof at the bottom of the board, the lecturer can visualize that proving is a directed activity (rather than arbitrary series of logically connected steps). Compare the lecturer's initial outline of the proof with the eventual end product:
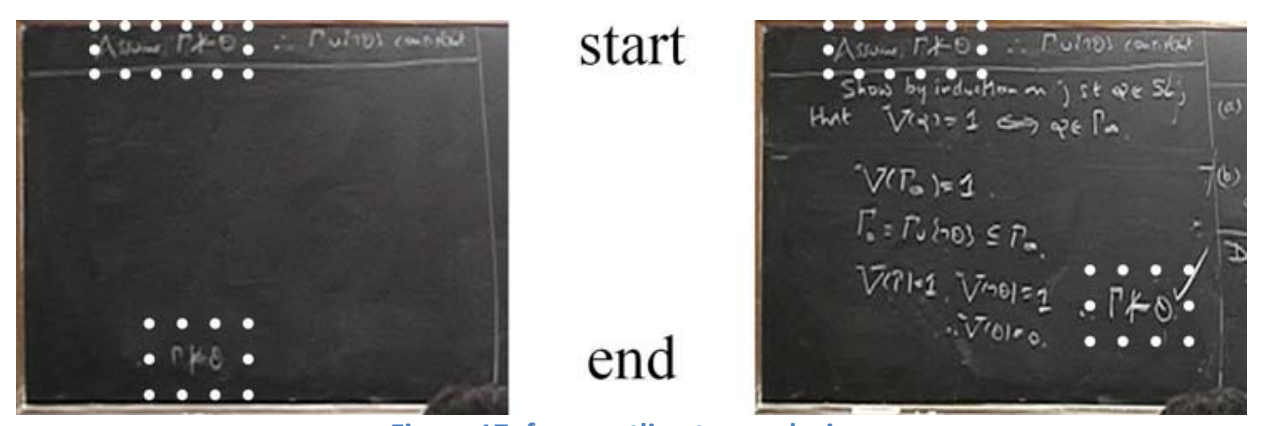

Figure 17: from outline to conclusion

The final 'line' of the proof (picture on the right) corresponds to the anticipated end in the outline (left picture). In moving from the outline to the conclusion, the lecturer has gradually filled in all the necessary 'steps along the ladder'.

\section{Conclusion}

A number of recent sociological studies have emphasized the embodied and material aspects of a diversity of practices and have tried to challenge Cartesian dualist views of a strict separation of mind and body. In particular, these studies have shown how what the mind does is in various ways shaped, determined, even constituted by the body and material artefacts. However, it could be argued that these studies have not yet entirely banished the idea that thinking and reasoning are mental, disembodied, and immaterial. The aim of this paper has been to extend the 'material turn' to an instance of abstract thought, using mathematical reasoning as a paradigmatic example.

This has been done by extending the 'laboratory studies' approach from the experimental sciences to the conceptual or mathematical sciences, something that faces particular methodological challenges:

It is easy to study laboratory practices because they are so heavily equipped, so evidently collective, so obviously material, so clearly situated in specific times and spaces, so hesitant and costly. But the same is not true of mathematical practices: notions such as 'demonstration', 'modelling', 'proving', 'calculating', 'formalism', 'abstraction' resist being shifted from 
the role of indisputable resources to that of inspectable and accountable topics. (Latour, 2008, p. 444)

Whilst other studies have tried to turn mathematics into an inspectable and accountable topic by analysing the discussions and controversies surrounding finished products, e.g., over the validity of the computer-assisted proof of the Four-Colour Conjecture (MacKenzie, 2001) or the significance of a theorem about fuzzy logic (Rosental, 2008), this study has described in detail the practical process of mathematical reasoning, relying on video recordings of graduate lectures in mathematical logic (Greiffenhagen, 2008).

The first thing that may be surprising to anyone who has never attended a lecture in mathematics, is the sheer amount of writing that goes on. It is not untypical for a lecturer to fill several blackboards during a forty-five minute lecture. Furthermore, not only do lecturers write a lot, but what they write is also of a peculiar form, namely in a certain sense 'complete': if one took photographs of the blackboard at certain points in the lecture, it would be possible (for a mathematically competent reader) to recover the mathematical arguments purely on the basis of the writing on the blackboard. ${ }^{7}$ Krantz $(1999$, p. 41) formulates this as a recommendation of how a lecturer should write: "After you have filled a board, it should be neat enough and clear enough that you could snap a Polaroid snapshot and read the presentation from the Polaroid."

What this points to is that in mathematics 'writing' and 'thinking' are inextricably interwoven. As Rotman (1993, p. x) puts it: "[...] being thought in mathematics always comes woven into and inseparable from being written". In that sense, the most abstract of the sciences - mathematics - is perhaps more material than other disciplines. A purely oral lecture may be possible in philosophy or sociology, but very difficult in modern mathematics. The concepts and theories of mathematics in an important sense could not exist - at least discussed and communicated - without being written down in some medium.

Blackboards have particular affordances that lend themselves to the presentation of mathematics. One has to do with the size: since in many lecture theatres there is more than one blackboard, lecturers have a lot of space available, which allows lecturers to have a lot of material visible and to refer to it during the course of the development of an argument. Another has to do with the dynamic production of the mathematical reasoning. The aim of these lectures is not primarily to convey a number of 'facts' (as encapsulated in theorems), but rather a certain 'ability' (as captured in the proofs). The emphasis of these lectures is, to use Ryle's terminology, on knowledge-how rather than

\footnotetext{
${ }^{7}$ This is not to say that doing so would be easy. Mathematicians are not able to 'sight-read' an unfamiliar proof at normal speed, but have to work to understand a proof - which is why for Livingston (1986) the written proof is, in a different sense, 'incomplete', since it does not contain the 'lived work' of working through the proof.
} 
knowledge-that, i.e., an orientation to proving as a process rather than proofs as a product (Lucas, 2000, pp. 366-367).

This paper has focused on the 'inscription practices' (Latour, 1986) used in presenting mathematics at the blackboard, such as the drawing of lines and boxes, providing a visual architecture of the main line of the proof, while reserving particular regions for specific purposes (established results, the main proof, 'side proofs'). Apart from the ones mentioned in this paper, there are other inscription practices in mathematics, most notably, diagrams. Although, as Shin $(1994$, p. 1) notes, there is a general prejudice against diagrams among logicians and mathematicians, these are nevertheless a crucial aspect of some parts of their practice. For Netz (1999), the lettered diagram was an essential (but neglected) feature of the emergence of Greek mathematics, while Kaiser (2005) demonstrates how Feynman diagrams revolutionised theoretical physics. Even in this course, which was predominately concerned with symbolic writing, lecturers made occasional use of diagrams. For example, in the lecture prior to this one, the lecturer had drawn the diagram in Figure 18 as a way of illustrating the general strategy of constructing the valuation needed for the proof (which consists of continuously dividing a set into two halves and selecting the 'correct' one).

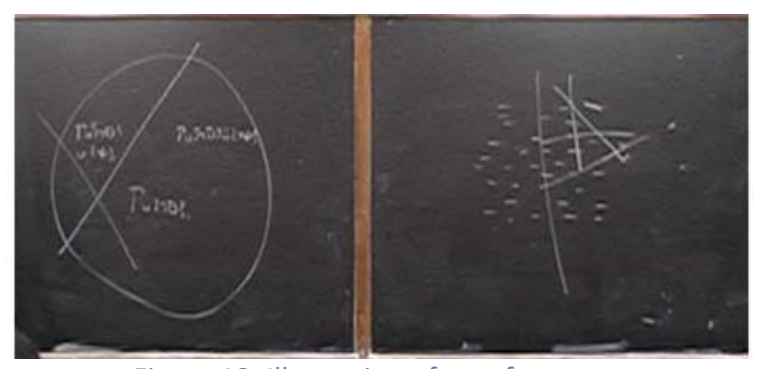

Figure 18: Illustration of proof strategy

How do the inscription practices of mathematics differ from those in other disciplines? Latour and Woolgar (1979, p. 51) invented the term 'inscription device' to characterize any apparatus which "can transform a material substance into a figure or diagram" (p. 51), such as a microscope, a spectrometer, or a microphone. Inscription devices are an essential aspect of work in the natural as well as the social sciences (Uprichard et al., 2008; Savage, 2008). In those sciences, inscriptions such as diagrams, tables, or symbols have been generated by intervening instruments out of various material substances (from rats to the talk produced by people). What is specific to mathematics (and other conceptual sciences) is the absence of inscription devices that transform materials into inscriptions, i.e., inscriptions on the blackboard have not been obtained through instruments out of material substances. In a sense, the material substances of mathematics are the inscriptions (and vice versa).

This may be why Wittgenstein $(1975, \S 157)$ once said "that in mathematics, the signs themselves do mathematics, they don't describe it". A mathematical proof is not a description of some kind of 
experiment. What is set out on the blackboard is not the report of an empirical investigation, but an argument - and a purportedly definitive one at that. The presented proof is currently accepted within its field and understood as foundational for other proofs in the field. The proof is not one that anyone in the lecture could challenge (although aspects may have been challenged during particular 'crises' in the discipline). A visual registering of the definitive character of the argument is the big tick at the end of this long proof: which other discipline could finish with such a definite full stop?

The fixed nature of the proof (as a step-by-step argument) is reflected in the fixed order of the presentation, which explains the strong ritualistic character of the lecture. Rituals are often associated with the idea of a rigidly required procedure, which certainly applies to the lecturer's exposition of this proof. The lecturer here is reciting an established argument by 'writing-talking' it at the board: he is neither providing a summary of the argument nor talking 'about' the argument, but instead is 'going over' the argument, i.e., doing it again.

By writing the argument down - in sometimes excruciating detail - the argument becomes inspectable and surveyable. In order to understand a (complicated) logical argument, one has to be able to see how the different parts are interconnected. This is why Goody argued that the development of formal logic was tied to the development of alphabetic writing - since this made it possible to trace and review sequences of steps in arguments. The proof is in a very real sense a material object, which is laid out on one or several pages, which has a 'beginning' and an 'end' which have physical location ("bottom of the page") and which despite its linear structure contains a variety of cross-references, which need to be inspectable (with a written paper, by 'flipping back and forth', in a lecture, by keeping it visible on one of the several blackboards).

The lecturer uses various resources to help students 'see' the mathematics, in particular, the inscription practices described in this paper. Another resource are the lecturer's body, arms, and hands, which are not just used to write at the blackboard, but also to point (as in Figure 5) or to visualize mathematical concepts (as in Figure 12). The lecturer can thus use his body in various ways to connect items on the board, highlight important things, and draw gestures over the symbols on the board or simply in the air (these important aspects will be discussed in a separate paper).

In sum mathematics really is "thinking with eyes and hands" (Latour, 1986). Understanding mathematics is tied to being able to inspect and survey the written symbols. Thinking in mathematics is inextricably interwoven with writing mathematics. 


\section{Acknowledgements}

I am immensely grateful to the lecturers and students who allowed me to observe and record the lectures and who more generally helped with the research. I also would like to thank the many mathematicians who answered my questions about the current use of blackboards in mathematics and provided access to relevant materials.

I started work on this paper when I was a Visiting Fellow at the ICAR (Interactions, Corpora, Learning and Representations) Lab in Lyon. I would like to thank Prof. Lorenza Mondada for making that visit possible and providing such a stimulating research environment. Earlier versions of this paper were presented at the Workshop Writing in Interaction in Lyon, France (November 30, 2007), a Seminar at the TU Berlin, Germany (October 20, 2010), and the Workshop Analyzing Visual Data in Klagenfurt, Austria (June $3 / 4,2011$ ). I would like to thank the participants for their comments and criticisms.

In working on subsequent versions of this paper, I have benefited from the feedback of Denis Chang, Edwin Coleman, Jacqueline Eke, Kornelia Engert, Michael Guggenheim, Christian Heath, Jonas Ivarsson, Christian Kiesow, Michael Liegl, Mike Lynch, Wes Sharrock, Hendrik Vollmer, Alan Warde, and two anonymous reviewers. Many thanks to all of them!

Part of this research was supported through a British Academy Postdoctoral Fellowship and a Simon Research Fellowship (funded through an endowment made to the University of Manchester).

\section{References}

Barany, M. J. and D. Mackenzie (forthcoming). Chalk: materials and concepts in mathematics research.

Barthes, R. (1972 [1957]). Mythologies. New York: Noonday Press.

Bloor, D. (1976). Knowledge and Social Imagery. London: Routledge \& Kegan Paul.

Coleman, E. (1988). The Role of Notation in Mathematics. Ph. D. thesis, Department of Philosophy, University of Adelaide.

Coleman, E. (1990). Paragraphy. Information Design Journal 6 (2), 131-146.

Dant, T. (2006). Material civilization: things and society. British Journal of Sociology 57 (2), 289-308.

Gillman, L. (1987). Writing Mathematics Well: A Manual for Authors. Washington, DC: Mathematical Association of America.

Goody, J. (1973). Evolution and communication: the domestication of the savage mind. British Journal of Sociology 24 (1), 1-12.

Goody, J. (1977). The Domestication of the Savage Mind. Cambridge: Cambridge University Press.

Greiffenhagen, C. (2000). From traditional blackboards to interactive whiteboards: a pilot study to inform system design. Proceedings of the 24th Conference of the International Group for the Psychology of Mathematics Education (PME-24, Hiroshima, Japan, July 23-27, 2000), Volume 2, pp. 305-313.

Greiffenhagen, C. (2008). Video analysis of mathematical practice? Different attempts to 'open up' mathematics for sociological investigation. Forum: Qualitative Social Research 9 (3).

Greiffenhagen, C. and W. Sharrock (2011). Does mathematics look certain in the front, but fallible in the back? Social Studies of Science 41 (6), 839-866. 
Halmos, P. R. (1970). How to write mathematics. L'Enseignement Mathématique 16, 123-152.

Hamilton, D. (1990). Learning about Education: An Unfinished Curriculum. Milton Keynes: Open University Press.

Heath, C., H. Knoblauch, and P. Luff (2000). Technology and social interaction: the emergence of 'workplace studies'. British Journal of Sociology 51 (2), 299-320.

Heintz, B. (2000). Die Innenwelt der Mathematik: Zur Kultur und Praxis einer beweisenden Disziplin. Wien: Springer.

Hutchins, E. (1995). Cognition in the Wild. Cambridge, MA: MIT Press.

Kaiser, D. (2005). Drawing Theories Apart: The Dispersion of Feynman Diagrams in Postwar Physics. Chicago: University Of Chicago Press.

Kalthoff, H., und T. Roehl (2011). Interobjectivity and interactivity: material objects and discourse in class. Human Studies 34 (4), 451-469.

Kidwell, P. A., A. Ackerberg-Hastings, and D. L. Roberts (2008). The blackboard: an indispensable necessity. In Tools of American Teaching, 1800-2000, pp. 21-34. Baltimore: John Hopkins University Press.

Krantz, S. G. (1999). How to Teach Mathematics (Second Ed.). Providence, RI: American Mathematical Society.

Latour, B. (1986). Visualization and cognition: thinking with eyes and hands. Knowledge and Society 6, 1-40.

Latour, B. (1987). Science in Action: How to Follow Scientists and Engineers through Society. Cambridge, MA: Harvard University Press.

Latour, B. (1992). Where are the missing masses? The sociology of a few mundane artifacts. In W. E. Bijker and J. Law (Eds.), Shaping Technology/Building Society: Studies in Sociotechnical Change, pp. 225-259. Cambridge, MA: MIT Press.

Latour, B. (2000). When things strike back: a possible contribution of 'science studies' to the social sciences. British Journal of Sociology 51 (1), 107-123.

Latour, B. (2008). The Netz-works of Greek deductions. Social Studies of Science 38 (3), 441-459.

Latour, B. and S. Woolgar (1979). Laboratory Life: The Social Construction of Scientific Facts. Beverly Hills: Sage.

Lave, J. (1988). Cognition in Practice: Mind, Mathematics, and Culture in Everyday Life. Cambridge: Cambridge University Press.

Law, J. (2008). On sociology and STS. Sociological Review 56 (4), 623-649.

Livingston, E. (1986). The Ethnomethodological Foundations of Mathematics. London: Routledge.

Llewellyn, N. (2011). The gift in interaction: a study of 'picking up the bill'. British Journal of Sociology $62(4), 718-738$.

Lucas, J. R. (2000). The Conceptual Roots of Mathematics: An Essay on the Philosophy of Mathematics. London: Routledge.

MacKenzie, D. (2001). Mechanizing Proof: Computing, Risk, and Trust. Cambridge, MA: MIT Press.

Nemirovsky, R. and Smith, M. (2011). The physicality of symbol-use. In S. Brown, S. Larsen, K. K. Marrongelle, and M. Oehrtman (Eds.), 14th Annual Conference Research in Undergraduate Mathematics Education (February 24-27, 2011, Portland, Oregon).

Netz, R. (1999). The Shaping of Deduction in Greek Mathematics: A Study in Cognitive History. Cambridge: Cambridge University Press.

Ochs, E., S. Jacoby, and P. Gonzalez (1994). Interpretive journeys: how physicists talk and travel through graphic space. Configurations 2 (1), 151-171.

Pitsch, K. (2007): Unterrichtskommunikation revisited: Tafelskizzen als interaktionale Ressource. Bulletin Suisse de Linguistique Appliquée 85, 59-80.

Rosental, C. (2008). Weaving Self-Evidence: A Sociology of Logic. Princeton: Princeton University Press.

Rotman, B. (1993). Ad Infinitum ... The Ghost in Turing's Machine. Stanford, CA: Stanford University Press.

Savage, M. (2008). Elizabeth Bott and the formation of modern British sociology. Sociological Review 56 (4), 579-605. 
Shin, S.-J. (1994). The Logical Status of Diagrams. Cambridge: Cambridge University Press.

Suchman, L. and R. Trigg (1993). Artificial intelligence as craftwork. In S. Chaiklin and J. Lave (Eds.), Understanding Practice: Perspectives on Activity and Context, pp. 144-178. Cambridge: Cambridge University Press.

Uprichard, E., R. Burrows, and D. Byrne (2008). SPSS as an 'inscription device': from causality to description? Sociological Review 56 (4), 606 - 622.

Warwick, A. (2003). Masters of Theory: Cambridge and the Rise of Mathematical Physics. Chicago: University of Chicago Press.

Weber, K. (2004). Traditional instruction in advanced mathematics courses: a case study of one professor's lectures and proofs in an introductory real analysis course. Journal of Mathematical Behavior 23 (2), 115-133.

Wittgenstein, L. (1975). Philosophical Remarks. Oxford: Basil Blackwell.

Wittgenstein, L. (1978). Remarks on the Foundations of Mathematics (Third ed.). Oxford: Basil Blackwell.

Wylie, C. D. (2012). Teaching manuals and the blackboard: accessing historical classroom practices. History of Education 41 (2), 257-272. 